\title{
Somatosensory evoked potentials following nerve and segmental stimulation do not confirm cervical radiculopathy with sensory deficit
}

\author{
URS D SCHMID, CHRISTIAN W HESS, HANS-PETER LUDIN \\ From the Department of Neurology and Neurosurgery, University Hospital, Berne, Switzerland
}

SUMMARY Twenty eight patients with unilateral cervical radiculopathy were studied by somatosensory evoked potentials (SEPs) from nerve stimulation at the wrist and from skin stimulation at the first, third or fifth finger depending on the root involved. In order to evaluate the reliability of various "radicular SEP patterns" as described in the literature, absolute latencies and side-to-side differences of the brachial plexus component from the supraclavicular fossa (N9), the medullary component (N13) from the cervical vertebra Cv7, and the primary cortical component (N20, P25) were assessed. Side-to-side differences of the amplitudes of N20/P25 and of the conduction times across the intervertebral fossa (interval N9-N13) were analysed. After nerve stimulation, $68 \%$ of the patients had false negative findings on the symptomatic, while $36 \%$ had positive findings on the asymptomatic side. After segmental stimulation, $72 \%$ of the patients had false negative findings on the symptomatic, while $22 \%$ had positive findings on the asymptomatic side. It is concluded that SEPs following nerve and segmental stimulation do not reliably confirm clear-cut already established diagnoses of unilateral radiculopathy with sensory and motor deficit. Therefore, they will not be helpful in the electrophysiological investigation of cervicobrachialgias of unknown origin.

Several electrophysiological methods are employed in the diagnosis of cervical radiculopathy. Needle electromyography and electroneurography are helpful in that they may show a segmental pattern of denervation in muscles when nerve conduction studies are normal. However, the diagnostic yield of these methods remains limited because they cannot provide direct proof of impaired nerve conduction in the very proximal segment of peripheral nerves. ${ }^{1-3}$ With the technique of somatosensory evoked potentials (SEPs) the sensory pathways can be assessed along the whole of their course from the peripheral nerve to the contralateral hemisphere. Hence, SEPs have been used in patients with cervical radiculopathy by several authors. ${ }^{1-16}$ Increased conduction time between the plexus component and the first medullary component, ${ }^{89}$ diminished amplitude ${ }^{6-10}$ or deletion of the first medullary, ${ }^{2}$ as well as diminished amplitude

Address and address for reprint requests: Dr Med. Urs D Schmid, Department of Neurosurgery, University-Hospital, CH-3010, Berne, Switzerland

Received 5 June 1987 and in revised form 23 July 1987. Accepted 27 July 1987 or deletion of the primary cortical component ${ }^{2}{ }_{7}$ have been described as indicating cervical root lesions, whereas other authors failed to find any SEP alterations in cervical radiculopathies. ${ }^{15}$ The sensitivity of the SEP was found to be higher when considering the intraindividual side-to-side differences. ${ }^{3710}$ In single root lesions, SEP from segmental stimulation of the skin, which requires averaging of a greater number of samples, was reported to be superior to SEP from nerve stimulation at the wrist, ${ }^{71213}$ and correct positive results of $50 \%,{ }^{12}$ $57 \%,{ }^{3}$ or $86.6 \%{ }^{7}$ in segmental SEP have been reported. Only a few of these investigations are based on larger groups of patients, ${ }^{237}$ and reports giving detailed analysis of the rate of correct negative and false positive or negative SEP findings are rarely given. $^{23}$

The question of diagnostic reliability of these SEPpatterns is of obvious importance. We therefore prospectively examined a series of 28 patients with clear-cut one-sided cervical radiculopathies and radicular sensory and motor deficits, using SEP from nerve stimulation at the wrist and from segmental stimulation at the fingers on both sides. 
Table 1 Clinical signs indicating cervical root impairment

Sensory and motor deficit and reflex abolished

Sensory and motor deficit

Sensory deficit and reflex abolished

Sensory deficit alone

Motor deficit and refiex abolished

Motor deficit alone

Total

\section{Material and methods}

Twenty eight patients ranging in age from 25 to 70 years (mean 45,8 years, 16 males) were studied. The history of cervicobrachialgia lasted over periods of 14 days to 17 years, with typical symptoms of cervical radiculopathy. Only cases with strictly unilateral clinical signs and with symptoms of unilateral functional impairment of one or two cervical roots were included: seven patients with $\mathrm{C} 6$ radioculopathy, nine with $\mathrm{C} 7$ radiculopathy, four with $\mathrm{C} 8$ radiculopathy, six with mixed $\mathrm{C} 7 / \mathrm{C} 8$ radiculopathy and one with mixed $\mathrm{C} 6 / \mathrm{C} 7$ radiculopathy. Patients with peripheral neuropathy or cervical myelopathy were excluded. The neurological deficits of various degrees are summarised in table 1 . With the exception of three patients, all had radicular sensory deficit. In all but two patients, clinical diagnosis was complemented by radiological and/or intraoperative findings. The subsequent treatment was not influenced by the SEP findings, and was conservative in 17 patients, and surgical in 11 patients.

On the 28 patients, 44 investigations were performed $(88$ sides). Twenty two patients had a total of 26 investigations ( 52 sides) following nerve stimulation at the wrist; 18 median nerve stimulations ( 36 sides), and eight ulnar nerve stimulations (16 sides); four of these 22 patients had both SEPs after median as well as ulnar stimulation. In 18 patients SEPs from segmental stimulation at the fingers were recorded (36 sides), 12 of which had both nerve and segmental stimulation. Twenty healthy subjects ranging in age from 16 to 52 (mean 27.6 years) served as a control group for SEPs from stimulation of the nerve at the wrist. ${ }^{5}$ For the segmental stimulation, normal values of Synek $^{16}$ served as controls.

\section{Stimulation and recording procedures}

The patients and subjects were comfortably positioned on a bed in a quiet room with their eyes closed. No muscle relaxants, analgesic or sedative drugs were used. Roomtemperature was about $23^{\circ} \mathrm{C}$.

For nerve stimulation at the wrist, electrical pulses of $0.2 \mathrm{~ms}$ duration were applied over the median or ulnar nerve with surface electrodes (cathode $2.3 \mathrm{~cm}$ proximal to the anode) at a rate of $3 / \mathrm{s}$ with a stimulus intensity of $4 \mathrm{~mA}$ above the motor threshold of the thenar or hypothenar muscles respectively.

For segmental stimulation, a pair of ring electrodes was attached to one finger with the cathode at the proximal interphalangeal and the anode at the distal interphalangeal joint. Depending on the clinical diagnosis, the electrodes were attached to the thumb, to the third or the fifth finger for stimulation of the sensory skin supply of the 6th, 7th, or 8th cervical root respectively. Stimulus intensity was 3-4 times the sensory threshold which was always below pain threshold. The pulse duration was $0 \cdot 2 \mathrm{~ms}$ and stimulation rate was $3 / \mathbf{s}$.
For recording, needle electrodes were placed over the ipsilateral supraclavicular fossa (SF), the 7th cervical vertebra (Cv7), and over the contralateral parieto-occipital scalp (Cx), $2 \mathrm{~cm}$ posterior to $\mathrm{C} 3 / \mathrm{C} 4$ placement according to the 10-20 system. The reference electrodes were placed at $\mathrm{Fz}$ (10-20 system) for the $\mathrm{Cv} 7$ recording and at the contralateral ear lobe for the SF recording. Two different montages were simultaneously used for the $\mathrm{Cx}$ recording, one with reference at $\mathrm{Fz}$ and one with reference at the contralateral ear lobe. The former was used for measurement of the cortical component, the latter helped identify the medullary components. The electrode impedance was kept below $3 \mathrm{k} \Omega$ in all recordings by means of careful skin preparation.

The signals were amplified and averaged by a conventional four channel recording machine (Medelec ER 94a) except for eight cases, where SEPs from nerve stimulation were recorded using a two channel machine (DISA System-15). Filtering bandpass was $5-2000 \mathrm{~Hz}$ for the $\mathrm{Cx}$ recording and $20-1000 \mathrm{~Hz}$ for the $\mathrm{Cv} 7$ and SF recording. To assess reproducibility, on each side 2-3 recordings of 256 to 512 stimuli were averaged for SEPs from nerve stimulation and of 1012 to 2024 stimuli were averaged for SEPs from segmental stimulation.

\section{Evaluation}

The SEP components from nerve stimulation at the wrist were named according to the normal mean peak latencies of the negative peaks as follows. N9 (supraclavicular electrode), $\mathrm{N} 13$ (spinal electrode), and N20 (cortical electrode). ${ }^{2-10}$ The same nomenclature was used for the analogous SEP components from segmental stimulation regardless of their longer latencies. The amplitude of the cortical component was measured peak-to-peak from N20 to the adjacent positive maximum P25.

Comparing the two or three consecutive recordings of identical stimulation site, components were defined reproducible if they showed similar wave forms and peak latencies which did not differ by more than $1 \mathrm{~ms}$ for the cervical and $3 \mathrm{~ms}$ for cortical components respectively, and a mean of the two or three values was taken for the analysis. If the components were not reproducible by this definition, they were rated as "not obtained". When the corresponding components were reproducible, proximal sensory conduction time across the intervertebral foramen from the latency interval N9-N13 and side-to-side differences were calcuated.

Latencies, conduction times, amplitudes and the side-toside differences $(\Delta)$ of SEPs from nerve stimulation were considered as prolonged when their value exceeded the mean plus 2.5 standard deviations (SD) of the normal values of the control group. ${ }^{5}$ The upper limits of normal were as follows: N9: $11.4 \mathrm{~ms}$; N13: $15.8 \mathrm{~ms}$; N20: 22.3 ms; N9-N13: $5.2 \mathrm{~ms}$; of the side-to-side differences: $\Delta \mathrm{N} 9: 0.56 \mathrm{~ms} ; \Delta \mathrm{N} 13: 0.7 \mathrm{~ms}$; $\Delta \mathrm{N} 20:-1 \cdot 1 \mathrm{~ms} ; \Delta \mathrm{N}$ 9-N13: $0.95 \mathrm{~ms}$; for the side-to-side difference of the amplitude $\Delta \mathrm{N} 20 / \mathrm{P} 25$. values of $50 \%$ or more were taken as abnormal.

For SEPs from segmental stimulation only side-to-side differences $(\Delta)$ were taken into consideration, since side-toside comparison in clinically unilateral radiculopathy has been considered to be most sensitive. ${ }^{237} \mathrm{~A}$ side-to-side difference was taken as abnormal when it exceeded the mean plus $4 \mathrm{SD},{ }^{16}$ that is $2 \mathrm{~ms}$ for $\Delta \mathrm{N} 13$ and $\Delta \mathrm{N} 20$. For the amplitude $\Delta \mathrm{N} 20 / \mathrm{P} 25,50 \%$ of the contralateral side, ${ }^{7}$ and for the 
Table 2 Nerve stimulation at the wrist: Reproducibility of components, absolute latencies, intervals, amplitudes and side-to-side differences ( $N$ of reproducible or calculable parameters/ $N$ of parameters evaluated)

\begin{tabular}{|c|c|c|c|c|c|c|}
\hline \multirow[t]{2}{*}{ Parameter } & \multicolumn{2}{|c|}{ Reproducibility of parameters } & \multicolumn{2}{|c|}{$\begin{array}{l}\text { Incidence of abnormal absolute } \\
\text { latencies and conduction-times }\end{array}$} & \multicolumn{2}{|c|}{$\begin{array}{l}\text { Incidence of abnormal side-to-side } \\
\text { differences of latencies, conduction times } \\
\text { and amplitudes* }\end{array}$} \\
\hline & $\begin{array}{l}\text { Symptomatic } \\
\text { side }\end{array}$ & $\begin{array}{l}\text { Asymptomatic } \\
\text { side }\end{array}$ & $\begin{array}{l}\text { Symptomatic } \\
\text { side }\end{array}$ & $\begin{array}{l}\text { Asymptomatic } \\
\text { side }\end{array}$ & $\begin{array}{l}\text { Symptomatic } \\
\text { side }\end{array}$ & $\begin{array}{l}\text { Asymptomatic } \\
\text { side }\end{array}$ \\
\hline $\begin{array}{l}\text { N9 } \\
\text { N13 } \\
\text { N20 } \\
\text { N9-N13 } \\
\text { N20/P25 }\end{array}$ & $\begin{array}{l}21 / 21 \\
25 / 26 \\
26 / 26 \\
21 / 21 \\
22 / 22\end{array}$ & $\begin{array}{l}19 / 21 \\
24 / 26 \\
26 / 26 \\
19 / 21 \\
22 / 22\end{array}$ & $\begin{array}{l}0 / 21 \\
0 / 25 \\
2 / 26 \\
2 / 21 \\
-\end{array}$ & $\begin{array}{l}0 / 19 \\
1 / 24 \\
0 / 26 \\
1 / 19 \\
-\end{array}$ & $\begin{array}{l}1 / 19 \\
1 / 24 \\
2 / 26 \\
1 / 19 \\
2 / 22\end{array}$ & $\begin{array}{l}0 / 19 \\
3 / 24 \\
1 / 26 \\
3 / 19 \\
1 / 22\end{array}$ \\
\hline
\end{tabular}

*Prolonged latencies and conduction times or diminished amplitudes compared with the contralateral side

Table 3 Segmental stimulation: Reproducibility of components, and side-to-side differences of latencies, conduction times and amplitudes (of reproducible or calculable parameters/of parameters evaluated)

\begin{tabular}{|c|c|c|c|c|}
\hline \multirow[t]{2}{*}{ Parameter } & \multicolumn{2}{|c|}{$\begin{array}{l}\text { Reproducibility of } \\
\text { parameters }\end{array}$} & \multicolumn{2}{|c|}{$\begin{array}{l}\text { Incidence of abnormal } \\
\text { side-to-side differences* }\end{array}$} \\
\hline & $\begin{array}{l}\text { symptomatic } \\
\text { side }\end{array}$ & $\begin{array}{l}\text { asymptomatic } \\
\text { side }\end{array}$ & $\begin{array}{l}\text { symp } \\
\text { side }\end{array}$ & $\begin{array}{l}\text { asymptomatic } \\
\text { side }\end{array}$ \\
\hline $\begin{array}{l}\text { N9 } \\
\text { N13 } \\
\text { N20 } \\
\text { N9-N13 } \\
\text { N20/P25 }\end{array}$ & $\begin{array}{r}7 / 18 \\
13 / 18 \\
18 / 18 \\
7 / 18 \\
17 / 17\end{array}$ & $\begin{array}{r}9 / 18 \\
16 / 18 \\
18 / 18 \\
8 / 18 \\
17 / 17\end{array}$ & $\begin{array}{l}0 / 5 \\
2 / 13 \\
2 / 18 \\
0 / 5 \\
3 / 17\end{array}$ & $\begin{array}{l}0 / 5 \\
0 / 13 \\
2 / 18 \\
1 / 5 \\
1 / 17\end{array}$ \\
\hline
\end{tabular}

*Prolonged latencies and conduction times or diminished amplitudes compared with the contralateral side

proximal sensory conduction time $\Delta$ N9-N13, 1 ms side-toside difference was defined as abnormal.

\section{Results}

SEPs from nerve stimulation at the wrist The frequency of reproducible components or evaluable parameters at the symptomatic as well as at the asymptomatic side from nerve stimulation are listed in table 2. All but five patients had all components reproducible, so that proximal sensory conduction time, amplitude of the primary cortical responses and side-to-side differences in 21 and 25 of the 26 patients were evaluable.

Table 2 gives also the incidence of abnormal latencies, conduction times and amplitudes at the symptomatic and asymptomatic side. Absolute latencies, conduction times and amplitudes were normal in all but five cases. Side-to-side comparison revealed prolonged N13 in one of 24 of the symptomatic, but also in three of 24 of the asymptomatic sides. Prolonged proximal conduction time N9-N13 was found in one of 19 of the symptomatic, and in three of 19 of the asymptomatic sides. N20/P25 was significantly reduced in two of 21 of the symptomatic, and in one of 21 of the asymptomatic sides.

In the patients as a group, there was no statistically? significant difference (paired $t$ test) between the two sides for the proximal conduction time N9-N13 $(p<0.375)$, N13 (p>0.4), and N20 (p<0.375).

Table 4 Accuracy* of various radicular SEP-patterns s $^{2-101213}$ in confirming unilateral cervical radiculopathies with neurological deficit

\begin{tabular}{|c|c|c|c|c|}
\hline \multirow[b]{2}{*}{ Radicular SEP-pattern } & \multicolumn{2}{|c|}{ Segmental stimulation $(n=18)$} & \multicolumn{2}{|c|}{ Nerve stimulation at the wrist $(n=26)$} \\
\hline & $\begin{array}{l}\text { found at the } \\
\text { symptomatic side } \\
\text { ("correct positive") }\end{array}$ & $\begin{array}{l}\text { found at the } \\
\text { asymptomatic side } \\
\text { ("false positive") }\end{array}$ & $\begin{array}{l}\text { found at the } \\
\text { symptomatic side } \\
\text { ("correct positive") }\end{array}$ & $\begin{array}{l}\text { found at the } \\
\text { asymptomatic side } \\
\text { ("false positive") }\end{array}$ \\
\hline $\begin{array}{l}\text { N13 abolished } \\
\text { N13 delayed } \dagger \\
\Delta \mathrm{N} 13 \text { delayed } \dagger\end{array}$ & $\begin{array}{l}\frac{28 \%}{15 \%} \\
\frac{1}{15}\end{array}$ & $\frac{11 \%}{0 \%}$ & $\begin{array}{l}4 \% \\
0 \% \\
4 \%\end{array}$ & $\begin{array}{r}8 \% \\
4 \% \\
12 \%\end{array}$ \\
\hline $\begin{array}{l}\mathrm{N} 20 \text { abolished } \\
\Delta \mathrm{N} 20 / \mathrm{P} 25 \text { reduced } \dagger \\
\mathrm{N} 20 \text { delayed } \dagger \\
\Delta \mathrm{N} 20 \text { delayed } \dagger\end{array}$ & $\begin{array}{r}0 \% \\
18 \% \\
11 \%\end{array}$ & $\begin{array}{r}0 \% \\
6 \% \\
11 \%\end{array}$ & $\begin{array}{l}0 \% \\
9 \% \\
8 \% \\
8 \%\end{array}$ & $\begin{array}{l}0 \% \\
5 \% \\
0 \% \\
4 \%\end{array}$ \\
\hline $\begin{array}{l}\text { N9-N13 prolonged } \dagger \\
\Delta \text { N9-N13 prolonged }+\end{array}$ & $\overline{0 \%}$ & $\overline{25} \%$ & $\begin{array}{r}10 \% \\
5 \%\end{array}$ & $\begin{array}{r}5 \% \\
16 \%\end{array}$ \\
\hline $\begin{array}{l}\text { Total of patients with } \\
\text { "radicular SEP signs" } \ddagger\end{array}$ & $28 \%$ & $22 \%$ & $32 \%$ & $36 \%$ \\
\hline
\end{tabular}

* percentage of patients after segmental and nerve stimulation respectively

tpercentage of the number of patients where the respective parameters were reproducible

łpercentage of patients where one or more "radicular SEP signs" were positive 
$S E P$ from segmental stimulation:

The frequency of reproducible components and evaluable parameters following segmental stimulation are listed in table 3. Of the 18 patients, N9 was obtained in seven of the symptomatic and in nine of the asymptomatic sides, and N13 was reproducible in 13 of the symptomatic, and in 16 of the asymptomatic sides. Therefore, a proximal sensory conduction time was calculable in seven and eight cases respectively, while side-to-side comparison for N13 and for N9-N13 remained possible in only 13 and five patients respectively.

The incidence of abnormal side-to-side-differences is listed in table 3 . In the cases where side-to-side comparison remained possible, the values failed to point to the symptomatic side, and the amplitude N20/P25 in 17 patients was reduced only in three of the symptomatic, and in one of the asymptomatic sides.

In the patients as a group, no significantly prolonged latencies of the medullary components $\mathrm{N} 13$ ( $p>0 \cdot 4$, paired $t$ test) or cortical components $\mathrm{N} 20$ ( $\mathrm{p}<0.375$, paired $t$ test), and no significantly prolonged proximal conduction time $\mathrm{N} 9-\mathrm{N} 13(\mathrm{p}=0 \cdot 1$, Wilcoxon-Mann-Whitney U Test), could be demonstrated on the clinically symptomatic side.

In 11 cases with a clinical and neuroradiological diagnosis of cervical radiculopathy, nerve root compression was verified during surgery. Taking only these surgically verified compressive root lesions, all with sensory deficit, the incidence of abnormal values obtained from the clinically symptomatic sides remained unchanged.

\section{Discussion}

The aim of this study was to examine the usefulness of SEPs in the diagnosis of compressive cervical root lesions. SEPs following nerve stimulation at the wrist and/or segmental stimulation of a finger were used in 28 patients. All presented with clear-cut unilateral cervical radiculopathies with neurological deficit of various degrees, and all but three had a sensory deficit. Either the median or ulnar nerve and the first, third, or fifth finger were stimulated according to the cervical root involved.

SEPs from nerve stimulation were mostly normal on the clinically symptomatic side of these patients, and this was particularly so for the proximal conduction time N9-N13. This finding is in contrast to previously reported investigations, ${ }^{689}$ but confirms the negative findings of others. ${ }^{15}$ Although not a specific sign, a prolonged conduction time across the cervical foramen due to compression-induced focal demyelination would have been the most convincing alteration indicating a cervical root lesion.

On the other hand, drop-out of damaged fibres and the greater temporal dispersion of afferent influx would result in amplitude diminution of the components. Diminished amplitude or deletion of primary medullary or cortical components have been described, ${ }^{23}$ and the latter is considered by some ${ }^{23} 7$ to be the only reliable SEP parameter in cases of cervical radiculopathy. But in view of the broad range of the amplitudes of evoked potentials in general, and of the cervical components in particular, the non-specific finding of an attenuated component is of limited value. Even if the side-to-side-differences were taken into consideration, amplitude reductions of $50 \%$ and more of the N20/P25 component when comparing with the contralateral side, or abolition of component N13, was a rare finding and occurred just as often on the symptomatic as on the asymptomatic side.

It follows that SEPs after nerve stimulation are not a sensitive diagnostic method for radiculopathy. It seems that a sufficient number of afferent nerve fibres contributing to the generation of cervical and cortical SEP components remain preserved, probably because they are using an entry other than that of the symptomatic root. The fast-conducting la afferents, which do not follow the segmental distribution of sensory skin supply, are preferentially stimulated at the wrist because of their low threshold. With median nerve stimulation in case of $\mathrm{C} 7$ radiculopathy or with ulnar nerve stimulation in case of $\mathrm{C} 8$ radiculopathy, these afferents will bypass a lesion affecting one or two roots at the cervical foramina.

On theoretical ground, this shortcoming should be ruled out by using segmental stimulation of the skin at a finger, as has been suggested by several authors. ${ }^{271316}$ Because of their smaller amplitude, segmental SEPs require more averages. Our results from segmental SEPs do show absence of cervical components in some cases, and this occurred more frequently on the symptomatic than on the asymptomatic side. But, because in an important number of patients either the plexus or the medullary component or both could not be obtained on either side, a side-toside comparison of the proximal sensory conduction time was impossible in $73 \%$ of the patients.

The frequent absence of the plexus component needs to be explained. It could be caused by a longstanding root compression due to retrograde degeneration when the damage is situated distal to the sensory ganglia. However, the fact that this component was also missing on the asymptomatic side in many instances points to a more technical reason. Although plexus and cervical components following segmental stimulation can safely be obtained in healthy subjects when a sufficient number of sweeps are averaged, ${ }^{16}$ good relaxation is crucial to minimise muscle interference, and this is difficult to achieve in patients who are in pain. 
Any attempt to compensate for muscle artefacts by assembling more averages will fail in these patients, because the longer duration of the recording process makes muscle relaxation more difficult, so that after some time of averaging, the base-line noise gets worse instead of better.

The cortical component N20/P25 proved to be very stable. N20 was obtained in all cases from segmental stimulation. Abnormal side-to-side differences of the amplitudes were observed in $4 / 17$ cases. But, while in three cases the amplitude was diminished on the clinically symptomatic, in one case the amplitude was diminished on the asymptomatic side. This finding contradicts the statements of some authors who consider diminished amplitude of the cortical component as most reliable sign in cervical radiculopathies. ${ }^{7}$

Of the 18 patients with segmental stimulation, five $(28 \%)$ had one or more abnormal SEP results on the symptomatic side, but this was also found in four $(22 \%)$ patients on the asymptomatic side. Even when taking the 11 surgical patients only, where the root compression was verified by neuroradiological investigation and during surgery, the results were only slightly better.

A possible explanation for the bilaterally affected plexus or medullary components would be the assumption that subclinical and radiologically silent involvement of the nerve root or of the spinal cord of the asymptomatic side cannot be completely ruled out. If

(a)

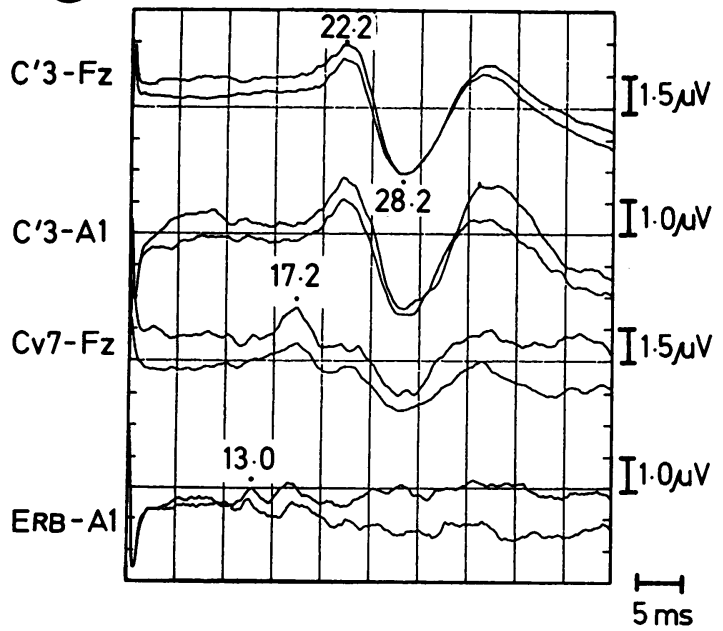

true, this would mean, that SEPs after segmental stimulation may detect even subclinical changes, yet such high sensitivity makes the method useless for clinical purposes.

\section{Conclusions}

In a group of patients with clear-cut cervical radiculopathy with unilateral neurological deficit including sensory impairment (table 1), a standard SEP technique was employed, and a "correct positive" SEP pattern as described in the literature was rarely found (table 4). Even when the segmental stimulation technique was used, $72 \%$ of the patients had false negative findings on the clinically symptomatic side, while $22 \%$ of the patients had positive "radicular SEP signs" on the asymptomatic side. The figure gives an example of such a false negative segmental SEP recording in a left sided cervical radiculopathy with sensory deficit. As SEP following nerve and segmental stimulation have only rarely confirmed a clear-cut cervical radiculopathy with sensory deficit, we do not expect them to be helpful in the electrophysiological investigation of doubtful cases of cervicobrachialgias.

The authors express their gratitude to Andrew Wade, for reviewing the English manuscript and to HansJürgen Reuter for his support.

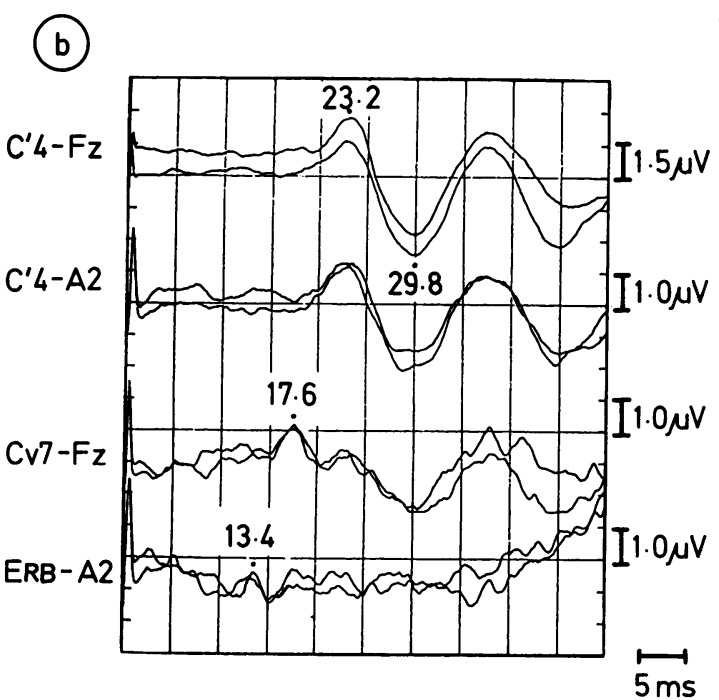

Fig Normal segmental SEP after stimulation of the left and right thumb of a 60 year old female with history of repeated left sided severe cervico-brachialgia for 1 year and signs of strictly left-sided cervical radiculopathy C6 with sensory and reflex deficit. Myelography and surgery revealed cervical disc herniation at the level C5/6. (a) symptomatic left side, (b) asymptomatic right side. 


\section{References}

1 Stöhr M, Buettner UW, Wiethölter H, Riffel B. Combined recording of compound action potentials and spinal cord evoked potentials in differential diagnosis of spinal root lesions. Arch Psychiat Nervenkr 1983;233:103-10.

2 Pilade JP, Pelissier J, Georgescu M, Simon L, et al. Spinal somesthetic evoked potentials and cervicobrachial neuralgia. Revue du Rhumatisme 1984;51:7-13.

3 Eisen A, Hoirch M, Moll A. Evaluation of radiculopathies by segmental stimulation and somatosensory evoked potentials. Can J Neurol Sci 1983;10:178-82.

4 Iragui VJ. The cervical somatosensory evoked potential in man. Electroencephalogr Clin Neurophysiol 1984;57:228-35.

5 Vlach L, Ludin HP. Spinale evozierte Potentiale beim Gesunden. Thesis 1982, University of Berne.

6 Stöhr J, Dichgans J, Diener HC, Buettner UW. Evozierte Potentiale. Heidelberg, Springer Verlag 1982. Chapter $1-2$.

7 Jörg J. Praktische SEP-Diagnostik. Stuttgart Enke Verlag (1983).

8 El Negamy E, Sedgwick EM. Delayed cervical somatosensory evoked potentials in cervical spondylosis. $J$ Neurol, Neurosurg, Psychiatry 1979;42:238-41.

9 Ganes T. Somatosensory conduction times and periph- eral, cervical and cortical evoked potentials in patients with cervical spondylosis. J Neurol, Neurosurg, Psychiatry 1980;43:683-9.

10 Siivola J, Sulg I, Heiskari M. Somatosensory evoked potentials in diagnostics of cervical spondylosis and herniated discs. Electroencephalogr Clin Neurophysiol 1981;52:276-82.

11 Hacke W, Stöhr M, Diener HCW, Buettner U. Recommendations for recording techniques regarding evoked potentials as a routine diagnostic procedure. $Z E E G$ EMG 1985;16:162-4.

12 Schramm J. Somatosensorisch evozierte Potentiale in der Differentialdiagnose spinaler Erkrankungen. In: Schramm J. Evozierte Potentiale in der Praxis. Heidelberg Springer-Verlag 1985;98-127.

13 Jörg J. SEP-Diagnostik in der Neurologie. Z EEG-EMG 1985;16:34-89.

14 Dal Bianco P, Mamoli B, Dorda W. The identification and variation of NSEP waveforms. Z EEG-EMG 1985;16:206-11.

15. Yu YL, Jones SJ. Somatosensory evoked potentials in cervical spondylosis. Correlation of median, ulnar and posterior tibial nerve components with clinical and radiological findings. Brain 1985;108:273-300.

16 Synek VM. Somatosensory evoked potentials after stimulation of digital nerves in upper limbs. Normative data Electroencephalogr Clin Neurophysiol 1986;65:460-3. 